\title{
Unusual association of two cases of acute myeloblastic leukaemia and possible Sjogren's syndrome and review of literature
}

\author{
Clement Brault ${ }^{1 *}$, Clement Gourguechon ${ }^{1}$, Mohamad Chehimi ${ }^{2}$, Anne Parcelier $^{2}$ and Jean-Pierre Marolleau ${ }^{2}$
}

*Correspondence: brault.clement@chu-amiens.fr

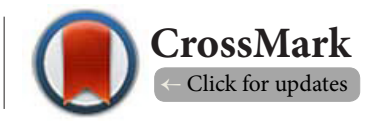

'Department of Internal Medicine, Amiens-Picardie University Hospital, place Victor Pauchet, F-80054 Amiens, France. ${ }^{2}$ Department of Clinical Haematology, Amiens-Picardie University Hospital, avenue Laennec, F-80000 Amiens, France.

\begin{abstract}
Sjögren's syndrome (SS) is frequently accompanied by hematologic complications, such as Hodgkin lymphoma. Here, we report on two unusual cases in which acute myeloid leukaemia (AML) and suspected SS occurred concomitantly. As has been observed for other malignancies, SS may be a paraneoplastic syndrome of AML.
\end{abstract}

Keywords: Sjögren’s syndrome, acute leukaemia, dry eyes and mouth syndrome

\section{Introduction}

Sjögren's syndrome (SS) is one of the most common autoimmune diseases, with a recently estimated prevalence in the general population of between $0.21 \%$ and $0.72 \%$ [1]. Sjogren's syndrome predominantly affects women, with a peak in incidence in the fifth decade of life [1]. The condition is characterized by lymphocytic infiltration of the exocrine glands and the production of autoantibodies. The clinical features are highly variable, although asthenia, dry mucous membranes, and painful muscles and joints predominate [2]. In 2002, the American-European Consensus Conference (AECC) published diagnostic criteria for SS [3]. Most recently, the American College of Rheumatology (ACR) and the European League Against Rheumatism (EULAR) developed a new set of classification criteria. These include the presence of objective immunological abnormalities (such as a focal lymphocytic sialadenitis in labial salivary gland biopsy, with a focus score of $\geq 1 \mathrm{foci} / 4 \mathrm{~mm}^{2} ; 3$ points), positivity for anti-sicca syndrome A (SSA) autoantibodies ( 3 points), and the presence of objective ocular signs (ocular staining score $\geq 5$ or Schirmer's test $\leq 5 \mathrm{~mm} / \mathrm{min}$ in at least one eye; 1 point) and oral signs (unstimulated whole saliva flow rate $\leq 0.1 \mathrm{~mL} / \mathrm{min} ; 1$ point). Patients with a total score of 4 or more are classified as having primary SS with a sensitivity of $96 \%$ and specificity of $95 \%$ [4].

Various haematological abnormalities (such as anaemia, thrombocytopenia and leukopenia, in the presence or absence of auto-immune disease) are frequently reported in patients with
SS [5-7]. The risk of developing non-Hodgkin's lymphoma in SS is well documented, and associations with other haematological malignancies, although uncommon, have been described $[8,9]$. Here, we report on two cases of the concomitant occurrence of acute leukaemia (AL) and suspected SS, and review the literature on this topic.

\section{Case presentation \\ Patient \# 1}

A 72-year-old woman with a history of obstructive sleep apnoea syndrome and extrapyramidal syndrome (but no associated dementia) presented with poor general health status, myelemia and pancytopenia (white blood count: $2.2 \times 10^{3} / \mathrm{mm}^{3}$; haemoglobin: $10 \mathrm{~g} / \mathrm{dl}$; platelet count: $147 \times 10^{3} / \mathrm{mm}^{3}$ ). She was hospitalized in the intensive care department for pneumoniarelated oxygen dependence. The myelogram revealed blast infiltration associated with acute myeloid leukaemia (AML) M4, according to the French-American-British (FAB) classification. Karyotyping revealed structural abnormalities and aneuploidy, including $5 q$ deletion.

When interviewed, the patient reported dry eye syndrome, foreign body sensation in the eye, dry mouth syndrome, and asthenia and apathy for few weeks. A salivary gland biopsy revealed lymphocytic sialadenitis with non-specific atrophic damage (Chisholm-Mason grade 2). A comprehensive biological screen was positive for antinuclear antibodies (positive titre of 
Brault et al. Hematology and Leukemia 2017,

http://www.hoajonline.com/journals/pdf/2052-434X-5-2.pdf

doi: $10.7243 / 2052-434 X-5-2$

1:320, anti-SSA antibodies) and negative for anti-DNA antibodies. Lymphocytic immunophenotyping detected moderate $B$ cell and CD8 T cell lymphopenia. The patient's poor general health status prevented us from performing confirmatory tests for SS. Although SS was strongly suspected, the ACR/ EULAR criteria were not met, and so our final diagnosis was possible SS. Following the onset of septic shock with multiorgan failure, and in view of the severity of the underlying disease, we decided to discontinue resuscitation. The patient died soon after.

\section{Patient \#2}

A 65-year-old man with history of aortic native valve endocarditis, chronic obstructive pulmonary disease and chronic exogenous had been monitored for several years following the occurrence of aregenerative anaemia and macrocytosis, in association with leukopenia, neutropenia, and mild thrombocytopenia. The results of a bone marrow examination were suggestive of alcohol intoxication and vitamin B9 and B12 deficiency. The man was admitted to hospital for treatment of the pancytopenia. A second bone marrow examination revealed blast infiltration and prompted a diagnosis of secondary AML. The karyotype was normal.

A clinical examination revealed dry mouth syndrome, with no other functional signs. The patient has experienced severe asthenia for the previous two months. We were not able to perform functional tests that might have confirmed the dry mouth and eyes syndrome. A salivary gland biopsy revealed the presence of non-specific, inflammatory lesions around the salivary ducts. Laboratory tests were positive for antinuclear antibodies (positive titre of 1:1280, anti-SSA antibodies) and negative for anti-DNA antibodies. The plasma protein electrophoresis results were not suggestive of hypoor hypergammaglobulinemia. The ACR/EULAR criteria were not met in this critically ill patient, and so our final diagnosis was possible SS. In view of the patient's poor general condition, comorbidities and the emergence of septic shock, we decided to discontinue chemotherapy. The patient died in the intensive care unit.

\section{Literature review}

Although many studies have focused on the risk of neoplasia in SS [10-14], we found only four publications in which acute leukaemia was cited (Table 1) [15-18]. The first publication reported on a 59-year-old woman with primary SS diagnosed in 1963. She developed myelodysplastic syndrome soon afterwards. AML was diagnosed in 1974 (i.e., 11 years after diagnosis of the autoimmune disease) [15]. The second publication described a 53-year-old woman with dry eyes and mouth syndrome. The Schirmer test and sialography results were abnormal. A salivary gland biopsy revealed unorganized lymphocyte infiltration. Two years after symptom onset, the patient developed fatal AML [16]. The third report concerned a 55-year-old man who developed acute lymphoblastic leukaemia (ALL) seven years after the onset of seronegative primary SS [17]. The last case concerned a 48-year-old male who developed acute B-cell leukaemia five years after the diagnosis of primary SS [18].

\section{Discussion}

We described two new cases of concomitant AL and possible SS. Four similar cases have been reported in the literature. Although our two patients presented with a dry eyes and mouth syndrome, a firm diagnosis of SS (according to the AECC or ACR/EULAR criteria) could not be made. SS cannot be diagnosed unless it is specifically screened for, and the documentation of dry eyes and mouth syndrome is often difficult in critically ill patients. A retrospective study of Swedish patients with "non-AECC" sicca syndrome did not observe an increased risk of cancer (standardized incidence ratio [95\% confidence interval]: 0.77 [0.41-1.32]). Interestingly, neither acute leukaemia nor lymphoma was diagnosed [11].

Patients with SS have a high prevalence of lymphoid haematological malignancies, such as chronic lymphocytic leukaemia, large granular lymphocytic (LGL) leukaemia and, above all, lymphoma [19-21]. In patients with LGL leukaemia, SS was the most frequently associated autoimmune disease (ahead of rheumatoid arthritis) [20]. Identical phenotypes of circulating lymphocytes and lymphocytes in the salivary glands may

Table 1. Characteristics of the present cases and those described in the literature.

\begin{tabular}{|c|c|c|c|c|c|c|c|}
\hline Patient & Sex & Reference & Age $^{*}$ (years) & Type of SS & Time interval $^{* *}$ & $\begin{array}{l}\text { Type of } \\
\text { leukaemia }\end{array}$ & Outcome \\
\hline 1 & $\mathrm{~F}$ & Patient \#1 & 72 & Possible SS & concomitant & $\mathrm{AML}$ & Death \\
\hline 2 & M & Patient \#2 & 65 & Possible SS & concomitant & AML & Death \\
\hline 3 & $\mathrm{~F}$ & {$[15]$} & 59 & AECC, primary & 11 years & AML & $?$ \\
\hline 4 & $\mathrm{~F}$ & {$[16]$} & 53 & AECC, primary & 2 years & AML & Death \\
\hline 5 & M & {$[17]$} & 55 & AECC, primary & 7 years & ALL & $?$ \\
\hline 6 & M & {$[18]$} & 43 & AECC, primary & 5 years & ALL & $?$ \\
\hline
\end{tabular}

F: female; M: male; SS: Sjögren’s syndrome; AECC: American-European Consensus Conference; AML: acute myeloid leukaemia; ALL: acute lymphoid leukaemia.

${ }^{*}$ Age at diagnosis of SS. ${ }^{* *}$ Time interval between the diagnosis of SS and the emergence of acute leukaemia. 
suggest LGL infiltration of the salivary glands [21]. Although an association between SS and myeloid haematological malignancy is rare, cases of myelodysplastic syndrome, chronic myeloid leukaemia and chronic myelomonocytic leukaemia have already been described $[22,23]$.

In most cases, SS was diagnosed several years before leukaemia. The use of immunosuppressant and immunomodulatory drugs in SS with visceral damage or disabling dry eyes and mouth syndrome might influence the occurrence of haematological malignancies [24]. However, Lazarus et al. did not find any significant differences in the use of drugs like hydroxychloroquine, prednisone, azathioprine and methotrexate (the main compounds used to treat severe forms of SS) when comparing primary SS patients with versus without cancer [18].

SS lies on the boundary between autoimmunity and lymphoproliferation. In this context, development of ALL might be related to the emergence of an immortalized clone. The mechanisms underlying the formation of AML are more difficult to understand. Furthermore, the very low incidence of this association makes it difficult to perform fundamental research. Well-conducted epidemiological studies of the association between SS and AL are now warranted. However, the simultaneous occurrence of these two diseases is suggestive of a causal relationship. Two arguments notably indicate that the possible SS observed in our two patients can be viewed as a paraneoplastic syndrome: (i) the acute onset and rapid progression of SS, and (ii) the short time interval between the onset of the dry eyes and mouth syndrome and the occurrence of acute leukaemia. Some observations suggested the possible paraneoplastic character of SS $[25,26]$.

\section{Conclusion}

We described two uncommon cases of concomitant possible SS (dry eyes and mouth syndrome, and positivity for anti-SSA/Ro antibodies) and AML. Our patients' critical health status and subsequent death prevented us from evaluating all the ACR/EULAR criteria. The possible SS in our patients may have been a paraneoplastic syndrome.

\section{Competing interests}

The authors declare that they have no competing interests.

\section{Authors' contributions}

\begin{tabular}{|l|c|c|c|c|c|}
\hline Authors' contributions & CB & CG & MC & AP & JPM \\
\hline Research concept and design & -- & -- & -- & -- & -- \\
\hline Collection and/or assembly of data & $\checkmark$ & -- & $\checkmark$ & $\checkmark$ & -- \\
\hline Data analysis and interpretation & -- & -- & -- & -- & -- \\
\hline Writing the article & $\checkmark$ & $\checkmark$ & -- & -- & $\checkmark$ \\
\hline Critical revision of the article & $\checkmark$ & $\checkmark$ & $\checkmark$ & -- & $\checkmark$ \\
\hline Final approval of article & $\checkmark$ & $\checkmark$ & $\checkmark$ & $\checkmark$ & $\checkmark$ \\
\hline Statistical analysis & -- & -- & -- & -- & -- \\
\hline
\end{tabular}

\section{Publication history}

EIC: Evangelos Terpos, University of Athens School of Medicine, Greece. Received: 22-May-2017 Final Revised: 17-Jul-2017 Accepted: 22-Aug-2017 Published: 07-Sep-2017

\section{References}

1. Patel R and Shahane A. The epidemiology of Sjogren's syndrome. Clin Epidemiol. 2014; 6:247-55. | Article | PubMed Abstract | PubMed FullText

2. Fox RI. Sjögren's syndrome. Lancet. 2005; 366:321-31.

3. Vitali C, Bombardieri S, Jonsson R, Moutsopoulos HM, Alexander EL, Carsons SE, Daniels TE, Fox PC, Fox RI, Kassan SS, Pillemer SR, Talal N and Weisman MH. Classification criteria for Sjogren's syndrome: a revised version of the European criteria proposed by the American-European Consensus Group. Ann Rheum Dis. 2002; 61:554-8. I Article I PubMed Abstract | PubMed FullText

4. Shiboski CH, Shiboski SC, Seror R, Criswell LA, Labetoulle M, Lietman TM, Rasmussen A, Scofield H, Vitali C, Bowman SJ and Mariette X. 2016 American College of Rheumatology/European League Against Rheumatism classification criteria for primary Sjogren's syndrome: A consensus and data-driven methodology involving three international patient cohorts. Ann Rheum Dis. 2017; 76:9-16. | Article | PubMed

5. Kikawada M, Watanabe D, Kimura A, Hanyu $H$, Serizawa $H$ and Iwamoto T. Autoimmune hemolytic anemia in an elderly patient with primary Sjogren's syndrome. Intern Med. 2005; 44:1312-5. | Article | PubMed

6. Schattner A, Friedman J, Klepfish A and Berrebi A. Immune cytopenias as the presenting finding in primary Sjogren's syndrome. QJM. 2000; 93:825-9. | PubMed

7. Ramakrishna R, Chaudhuri K, Sturgess A and Manoharan A. Haematological manifestations of primary Sjogren's syndrome: a clinicopathological study. Q J Med. 1992; 83:547-54. | PubMed

8. Fragkioudaki S, Mavragani CP and Moutsopoulos HM. Predicting the risk for lymphoma development in Sjogren syndrome: An easy tool for clinical use. Medicine (Baltimore). 2016; 95:e3766. | Article | PubMed Abstract | PubMed FullText

9. Manganelli $P$, Fietta $P$ and Quaini F. Hematologic manifestations of primary Sjogren's syndrome. Clin Exp Rheumatol. 2006; 24:438-48. | Article I PubMed

10. Ioannidis JP, Vassiliou VA and Moutsopoulos HM. Long-term risk of mortality and lymphoproliferative disease and predictive classification of primary Sjogren's syndrome. Arthritis Rheum. 2002; 46:741-7. | Article I PubMed

11. Theander E, Henriksson G, Ljungberg O, Mandl T, Manthorpe R and Jacobsson LT. Lymphoma and other malignancies in primary Sjogren's syndrome: a cohort study on cancer incidence and lymphoma predictors. Ann Rheum Dis. 2006; 65:796-803. | Article | PubMed Abstract I PubMed FullText

12. Zhang W, Feng S, Yan S, Zhao Y, Li M, Sun J, Zhang FC, Cui Q and Dong Y. Incidence of malignancy in primary Sjogren's syndrome in a Chinese cohort. Rheumatology (Oxford). 2010; 49:571-7. I Article I PubMed

13. Weng MY, Huang YT, Liu MF and Lu TH. Incidence of cancer in a nationwide population cohort of 7852 patients with primary Sjogren's syndrome in Taiwan. Ann Rheum Dis. 2012; 71:524-7. | Article | PubMed

14. Abrol E, Gonzalez-Pulido C, Praena-Fernandez JM and Isenberg DA. A retrospective study of long-term outcomes in 152 patients with primary Sjogren's syndrome: 25-year experience. Clin Med (Lond). 2014; 14:15764. | Article | PubMed

15. DeCoteau WE, Katakkar SB, Skinnider L, Hayton RC and Somerville EA Sjogren's syndrome terminating as a myeloproliferative disorder. J Rheumatol. 1975; 2:331-5. | PubMed

16. Wakita H, Asai T, Nakamura M, Endoh N, Hiruma K, Igarashi T, Wong $\mathrm{P}$, Itoh $\mathrm{K}$ and Yoshida $\mathrm{S}$. [Development of acute myelocytic leukemia in the course of Sjogren's syndrome]. Rinsho Ketsueki. 1989; 30:56-60. | PubMed

17. Blanes A, Villar A, Amigo V, Monzo E and Gonzalez Sal M. [Primary Sjogren's syndrome in men: evolution to acute lymphoblastic leukemia]. An Med Interna. 1991; 8:605-8. I PubMed

18. Lazarus MN, Robinson D, Mak V, Moller H and Isenberg DA. Incidence of cancer in a cohort of patients with primary Sjogren's syndrome. Rheumatology (Oxford). 2006; 45:1012-5. | Article | PubMed

19. Brito-Zeron P, Kostov B, Fraile G, Caravia-Duran D, Maure B, Rascon 
Brault et al. Hematology and Leukemia 2017,

http://www.hoajonline.com/journals/pdf/2052-434X-5-2.pdf

FJ, Zamora M, Casanovas A, Lopez-Dupla M and Ripoll M et al. Characterization and risk estimate of cancer in patients with primary Sjogren syndrome. J Hematol Oncol. 2017; 10:90. | Article | PubMed Abstract | PubMed FullText

20. Friedman J, Schattner A, Shvidel L and Berrebi A. Characterization of T-cell large granular lymphocyte leukemia associated with Sjogren's syndrome-an important but under-recognized association. Semin Arthritis Rheum. 2006; 35:306-11. | Article | PubMed

21. Molad $Y$, Okon E, Stark $P$ and Prokocimer M. Sjogren's syndrome associated T cell large granular lymphocyte leukemia: a possible common etiopathogenesis. J Rheumatol. 2001; 28:2551-2. | Article | PubMed

22. Minowa R, Miyagawa S, Fukumoto T, Majima T, Shimoyama T, Fujimura $Y$ and Shirai T. Primary Sjogren's syndrome followed by chronic myelogenous leukemia: a case report with a ten year history. $J$ Dermatol. 1998; 25:460-4. | Article | PubMed

23. Ponge T, Champetier de Ribes F, Ponge A, Garand R and Cottin S. Chronic myelomonocytic leukemia and primary Sjogren's syndrome. Clin Rheumatol. 1988; 7:110-3. | PubMed

24. Hochberg MC and Shulman LE. Acute leukemia following cyclophosphamide therapy for Sjogren's syndrome. Johns Hopkins Med J. 1978; 142:211-4. | PubMed

25. Janssens L, Van Baarle A, Daelemans R and Verbraeken H. Paraneoplastic Sjogren's syndrome. Clin Rheumatol. 1987; 6:449-52. | PubMed

26. Bartoloni E, Alunno A and Gerli R. Primary Sjogren's syndrome as paraneoplastic disorder: a case report. Clin Exp Rheumatol. 2012; 30:454. | Article | PubMed

\section{Citation:}

Brault C, Gourguechon C, Chehimi M, Parcelier A and Marolleau J-P. Unusual association of two cases of acute myeloblastic leukaemia and possible Sjogren's syndrome and review of literature. Hematol Leuk. 2017; 5:2. http://dx.doi.org/10.7243/2052-434X-5-2 